\title{
Nivolumab with Vaccine in Ipilimumab-Refractory or -Naive Melanoma
}

\section{Mohamed L Elsaie*}

Department of Dermatology and Cutaneous Surgery, Miller School of Medicine, University of Miami, Miami, Florida 33140, USA

Cancer evolves to exploit multiple mechanisms in order to avoid immune-cell recognition and antitumor effector functions, thereby limiting the clinical benefits of immunotherapy strategies. Antibodies that square the inhibitory receptor cytotoxic T-lymphocyte-associated antigen 4 (Ctla-4, for example ipilimumab, have been indicated to discharge one of these negative invulnerable administrative pathways, expediting tough reactions in a subgroup of patients with metastatic melanoma and a by and large survival profit in patients with metastatic melanoma. The modified cell demise $1(\mathrm{Pd}-1)$ receptor is an alternate inhibitory receptor communicated by $\mathrm{T}$ units specially with enduring presentation to antigens. Its essential ligand, Pd-L1 (otherwise called B7-H1 or Cd274), is regularly communicated inside the tumor microenvironment, incorporating disease units and tumor-penetrating macrophages. The Pd-1 receptor has a second ligand, Pd-L2 (otherwise called B7-Dc or Cd273), that is especially communicated by antigenputting forth units. In tumor models, Pd-1 contrarily manages the effector stage of T-unit reactions after ligation of Pd-L1 communicated inside the tumor. It has been hypothesized that antibodies that piece the face to face time between Pd-1 and Pd-L1 in tumors might specially discharge the cytotoxic capacity of tumor-particular $\mathrm{T}$ units with fewer systemic dangerous impacts than those that are seen with other resistant checkpoint inhibitors [1].

Nivolumab, a human immunoglobulin G4-blocking neutralizer against the T-cell customized death-1 checkpoint protein, Pd-1, has movement against metastatic melanoma. Its wellbeing, clinical viability, and correlative biomarkers were as of late evaluated with or without a peptide antibody in ipilimumab-refractory and -naive melanoma. In patients with ipilimumab-refractory or -naive melanoma, nivolumab at $3 \mathrm{mg} / \mathrm{kg}$ with or without peptide immunization was overall endured and instigated reactions enduring up to 140 weeks [2].

In their Phase 1 as of late distributed study Weber et al. incorporated 90 patients with unresectable stage Iii or Iv melanoma who were ipilimumab gullible and had encountered movement after no less than one earlier treatment (associates 1 to 3, 34 patients) or encountered movement after former ipilimumab (companions 4 to 6 , 56 patients) appropriated nivolumab at 1,3 , or $10 \mathrm{mg} / \mathrm{kg}$ at regular intervals for 24 weeks, then like clockwork for up to 2 years, with or without a multipeptide immunization [3-6].

They presumed that Nivolumab with immunization was decently endured and protected whatsoever measurements. The Recist 1.1 reaction rate for both ipilimumab-hard-headed and -guileless patients was $25 \%$. Average span of reaction was not arrived at an average of 8.1 months of take after up high pretreatment Ny-Eso-1 and Mart1 -specific Cd8+ T cells were connected with movement of illness. At week 12, expanded fringe blood $\mathrm{T}$ administrative cells and diminished antigen-particular $\mathrm{T}$ units were connected with progression. pdL1 tumor staining was connected with reactions to nivolumab, yet negative staining did not preclude a reaction. Further; Patients who encountered movement after nivolumab could react to ipilimumab [4-8].

Reactions to nivolumab in ipilimumab-refractory patients or to ipilimumab in nivolumab-refractory patients help blending or sequencing of nivolumab and ipilimumab. The vitality of this work is that it prescribes that the $\mathrm{Pd}-1$ neutralizer nivolumab with or without a peptide immunization is decently endured after ipilimumab. The information demonstrate that one can accomplish the same reaction rate when ipilimumab gullible as when one is ipilimumab unmanageable and that the reactions are of long term. Patients with measurements restricting harmfulness to ipilimumab can appropriate nivolumab securely without reiterating the danger seen with ipilimumab. Interestingly, patients with previous $\mathrm{T}$ cell reactivity to melanoma antigens are more averse to react to nivolumab than patients with no or a low level of prior melanoma particular $\mathrm{T}$ units. The phenotype and function of those $\mathrm{T}$ cells are currently being investigated.

\section{References}

1. Hodi FS, O'Day SJ, McDermott DF, Weber RW, Sosman JA, et al. (2010) Improved survival with ipilimumab in patients with metastatic melanoma. N Engl J Med 363: 711-723.

2. Robert C, Thomas L, Bondarenko I, O'Day S, M D JW, et al. (2011) Ipilimumab plus dacarbazine for previously untreated metastatic melanoma. N Engl J Med 364: 2517-2526.

3. Pardoll DM (2012) The blockade of immune checkpoints in cancer immunotherapy. Nat Rev Cancer 12: 252-264.

4. Blank C, Brown I, Peterson AC, Spiotto M, Iwai Y, et al. (2004) PD-L1/B7H-1 inhibits the effector phase of tumor rejection by $T$ cell receptor (TCR) transgenic CD8+ T cells. Cancer Res 64: 1140-1145

5. Okazaki T, Honjo T (2007) PD-1 and PD-1 ligands: from discovery to clinical application. Int Immunol 19: 813-824.

6. Ribas A (2012) Tumor immunotherapy directed at PD-1. N Engl J Med 366 2517-2519.

7. Hamid O, Robert C, Daud A, Hodi FS, Hwu WJ, et al. (2013) Safety and tumor responses with lambrolizumab (anti-PD-1) in melanoma. N Engl J Med 369: 134-144.

8. Weber JS, Kudchadkar RR, Yu B, Gallenstein D, Horak CE, et al. (2013) Safety, Efficacy, and Biomarkers of Nivolumab With Vaccine in IpilimumabRefractory or -Naive Melanoma. J Clin Oncol 364: 2517-2526.
Corresponding author: Mohamed L Elsaie, Department of Dermatology and Cutaneous Surgery, Miller School of Medicine, University of Miami, Miami, Florida 33140, USA, Tel: 305-243-6734; E-mail: egydoc77@yahoo.com

Received October 29, 2013; Accepted November 02, 2013; Published November 04, 2013

Citation: Elsaie ML (2013) Nivolumab with Vaccine in Ipilimumab-Refractory or -Naive Melanoma. J Vaccines Vaccin 4: e124. doi: 10.4172/2157-7560.1000e124

Copyright: $\odot 2013$ Elsaie ML. This is an open-access article distributed under the terms of the Creative Commons Attribution License, which permits unrestricted use, distribution, and reproduction in any medium, provided the original author and source are credited. 